\title{
Enhanced diagnostic efficiency of the polymerase chain reaction by co-amplification of multiple regions of HIV-1 and HIV-2
}

\author{
Udaykumar $^{b}$, Alonso Heredia ${ }^{\mathrm{a}}$, Vincent Soriano ${ }^{\mathrm{c}}$, Rosa Bravo ${ }^{\mathrm{c}}$, \\ Jay S. Epstein ${ }^{\mathrm{a}}$, Indira K. Hewlett ${ }^{\mathrm{a}^{*}}$ \\ "Laboratory of Molecular Virology, Division of Transfusion and Trunsmitted Diseases, Center for Biologics \\ Evaluation and Research, Food and Drug Administration, 1401 Rockville Pike, Rockville, MD 20852-1448, \\ $U S A^{b}$ The University of Michigan Medical Center, MSRB 1, Room 4510, 1150 West Medical Center Drive, \\ Ann Arbor, MI 48109-0650, USA 'Service of Infectious Diseases, Microbiology and Immunology. \\ Instituto de Salud Carlos III. 28010 Madrid, Spain
}

Accepted 14 February 1994

\begin{abstract}
A method for co-amplification of multiple viral sequences of HIV-1 and HIV-2 by polymerase chain reaction was designed. The technique resulted in the spccific detection of each type of virus and allowed the amplification of as few as two copies of target DNA. The amplification of multiple regions of the viral genome offers the advantage of detecting multiple target sequences, which may be essential for some viruses, such as HIV, that exhibit a high degree of variability in their gene sequences. In addition, the method permitted the detection of both virus types in the same reaction, allowing for greater utility in geographic areas where coinfections with both viruses occur and cross-reactivity in Western blots is observed. This method was applied successfully to the detection of viral DNA in clinical specimens.
\end{abstract}

Key words: HIV-1; HIV-2; Polymerasse chain reaction; PCR; Coamplification; Coinfections

\section{Introduction}

The polymerase chain reaction (PCR) is a sensitive technique for the detection of nucleic acid. In AIDS, it has been used in the early detection of HIV infection, i.e. prior to antibody detection, for quantitation of viral load in the active disease stage,

FCorresponding author. Fax: +1 (301) 5946989 
for monitoring patients on antiviral therapy and for the discrimination of HIV-1 and HIV-2 infections in clinical specimens. Due to the considerable variability of HIV-1 (Goudsmit et al., 1991) and HIV-2 strains (Schulz et al., 1990) amplification of different regions of the genome with different sets of primers may be necessary for detection of the presence of viral DNA (Laure et al., 1988; Ou et al., 1988). These amplifications have conventionally been carried out as independent reactions. We have developed a method to amplify and detect three different genome regions of HIV-1 or HIV-2 in a single reaction. The method, termed multiplex PCR, is specific for each type of virus and detects as few as two or three copies of proviral DNA. Multiplex PCR also allows the detection of both viruses in a single reaction. In a study of limited numbers of clinical samples, this technique allowed sensitive and specific detection of HIV-I and HIV-2 in samples from infected individuals.

\section{Materials and methods}

\subsection{Specimens}

Blood specimens were collected from nine HIV-I infected and five HIV-2 infected individuals living in Spain. DNA was extracted by the proteinase $\mathrm{K} /$ phenol extraction method and PCR was carried out in the presence of $1 \mu \mathrm{g}$ of DNA.

Table 1: Primers and Probes Used in Multiplex PCR.

\begin{tabular}{|c|c|c|c|c|c|}
\hline SNO. & Region & Oligo* & Size (bp) & Location* & Sequence $\left(5^{\prime}->3^{n+*}\right.$ \\
\hline 1 & HIV-1 env & $\begin{array}{l}\text { SR61 } \\
\text { SR62 } \\
\text { SR63 }\end{array}$ & $\begin{array}{l}22 \\
23 \\
24\end{array}$ & $\begin{array}{l}7737-7758 \\
8043-8065 \\
7811 \cdot 7834\end{array}$ & $\begin{array}{l}\text { CCA CCA AGG CAA AGA GAA GAGT } \\
\text { CAC AG(CT) AGT GGT GCA AAT GAGT } \\
\text { GGA GCA GCA GGA AGC ACT ATG GGC }\end{array}$ \\
\hline 2 . & HV-2 env & $\begin{array}{l}\text { SR64 } \\
\text { SR65 } \\
\text { SR66 }\end{array}$ & $\begin{array}{l}24 \\
24 \\
27\end{array}$ & $\begin{array}{l}7868 \cdot 7891 \\
7952.7975 \\
7921.7947\end{array}$ & $\begin{array}{l}\text { CCT CCA GGC AAG AGT CAC TGC TAT } \\
\text { MC CAT GGT AGA GTA GTG TGG CAG } \\
\text { TAA AT CAT GGG GAT GTG CGT TTA GAC }\end{array}$ \\
\hline 3. & HIV.1 gag & $\begin{array}{l}\text { SR71 } \\
\text { SR72 } \\
\text { SR73 }\end{array}$ & $\begin{array}{l}22 \\
22 \\
22\end{array}$ & $\begin{array}{l}766-787 \\
844-865 \\
789-809\end{array}$ & $\begin{array}{l}\text { GCG GAG GCT AGA AGG AGA GAGA } \\
\text { TCT TTC CCC CTG GCC TTA ACCG } \\
\text { GGG TGC GAG AGC GTC AGT ATTA }\end{array}$ \\
\hline 4 & HV $2 \mathrm{gag}$ & $\begin{array}{l}\text { SR74 } \\
\text { SR75 } \\
\text { SR76 }\end{array}$ & $\begin{array}{l}21 \\
25 \\
25\end{array}$ & $\begin{array}{l}541-561 \\
908-932 \\
782-806\end{array}$ & $\begin{array}{l}\text { GGG AGA TGG GCG CGA GAA ACT } \\
\text { GCT AGG TGG TGC TGT TGG TCT ACTI } \\
\text { TAA TAC TGT CTG CGT CAT TTG GTGC }\end{array}$ \\
\hline 5. & Hilv-1 pol & $\begin{array}{l}\text { SR81 } \\
\text { SR82 } \\
\text { SR83 }\end{array}$ & $\begin{array}{l}27 \\
24 \\
25\end{array}$ & $\begin{array}{l}4778-4804 \\
4969-4992 \\
4820-4844\end{array}$ & $\begin{array}{l}\text { GGC AGT ATT CAT CCA CAA TT TAA AAG } \\
\text { CTA CTG CCC CTT CAC CTT TCC AGA } \\
\text { GGG GTA CAG TGC AGG GGA AAG AATA }\end{array}$ \\
\hline 6. & HV-2 pol & $\begin{array}{l}\text { SR84 } \\
\text { SR85 } \\
\text { SR86 }\end{array}$ & $\begin{array}{l}26 \\
26 \\
26 \\
\end{array}$ & $\begin{array}{l}4589-4614 \\
4796-4821 \\
4728-4753 \\
\end{array}$ & $\begin{array}{l}\text { ATA GCA GTT CAT TGC ATG AAT TT AA } \\
\text { GTC CCT ACC TTG ACT ATG ACT GCT CC } \\
\text { AGG TCT ATT (TALGA GAG AAG GCA GAG AT }\end{array}$ \\
\hline
\end{tabular}

* The first, scond and third oligos of each set represent the upper- and lower-primer and the probe, respectively.

** Based on the MN and Rod strains of HIV-1 and HIV-2, respectively.

*** The sequences of the down-stream primers represent the respective antisense sequences. Nucleotides in parenthesis indicate mixed site. 
Table 2: Lengths of the Amplified Fragments (bp)

\begin{tabular}{llll}
\hline S.No. & Region & HIV -1 & HIV - \\
\hline 1 & gag & 100 & 392 \\
2 & pol & 215 & 233 \\
3 & env & 329 & 108 \\
\hline
\end{tabular}

\subsection{Primer selection}

Primer sequences were selected from highly conserved nucleotide regions among different strains of HIV-1 or HIV-2 (Myers et al., 1992). Design of the primers was performed with the help of the software Oligo (National Biosciences, Plymouth, $\mathrm{MN}$ ). Special attention was paid to minimize the number of sequence mismatches among different strains of each virus (Grankvist et al., 1991a). To facilitate multiplex amplification, primers were designed so as to avoid complementary sequences and strong internal secondary structures. Selected primers and probes corresponding to the GAG, POL and ENV regions of HIV-1 and HIV-2 are shown in Table 1. Amplified fragments were designed to be different in size in order to facilitate their differentiation in a single reaction (Table 2).

\subsection{PCR amplification}

PCR amplification was performed following the Hot Start technique using Ampliwax PCR Gems (Perkin-Elmer Cetus, Norwalk, CN). To reduce the risk of contamination from previously amplified material, the Uracil $N$-glycosylase (UNG) method sustituting dTTP with dUTP (Perkin-Elmer Cetus) was incorporated into the system. Each reaction mixture consisted of $1 \mu \mathrm{g}$ of DNA, $10 \mathrm{mM}$ Tris-hydrochloric acid ( $\mathrm{pH} 8.3), 50 \mathrm{mM}$ potassium chloride, $0.2 \mathrm{mM}$ each deoxynucleotide triphosphate (dATP, dCTP, dGTP, dUTP), $1.5 \mathrm{mM}$ magnesium chloride, $0.25 \mu \mathrm{M}$ of each primer, 2.5 units of Amplitaq polymerase (Perkin-Elmer Cetus) and 1 unit of UNG (Gibco, Grand Island, NY). Thermocycling was carried out for $10 \mathrm{~min}$ at $37^{\circ} \mathrm{C}$ for 1 cycle, 4 min at $94^{\circ} \mathrm{C}$ for 1 cycle, linked to 3335 cycles at $94 \mathrm{C}$ for 1 $\min , 55^{\circ} \mathrm{C}$ for $1 \mathrm{~min}, 72^{\circ} \mathrm{C}$ for $1 \mathrm{~min}$. After the last cycle, reactions were either frozen immediately at $-20^{\circ} \mathrm{C}$ or linked to a soak file at $72^{\circ} \mathrm{C}$ until a few drops of chloroform were added to inactivate UNG.

\subsection{Detection of amplified fragments}

Depending on the number of primer pairs used for amplification, the PCR product should contain one, two or three amplified fragments. Amplified fragments were detected following the liquid hybridization method (Ehrlich et al., 1990) in a hybridization reaction containing one, two or three probes. Oligonucleotides selected as probes were ${ }^{32} \mathrm{P}$ end-labelled as described elsewhere (Sambrook et al., 1989), being two or three oligonucleotides labelled in the same reac- 


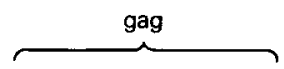

$100 \begin{array}{llll}10 & 3 & 2 & 1\end{array}$

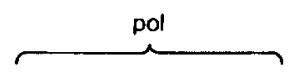

$\begin{array}{lllll}100 & 10 & 3 & 2 & 1\end{array}$

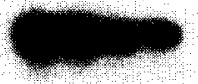

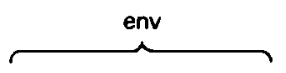

$10010 \quad 3 \quad 2 \quad 1$
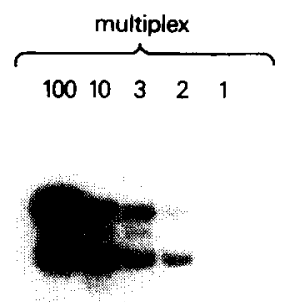

$-329 b P$

$-215 b P$

$-100 \mathrm{bP}$

Fig. 1. Single and multiplex PCR sensitivity for HIV-I amplification. The numbers on top indicate the copy number of Z6 plasmid. Genomic position and size of the amplified fragments are also indicated.

tion. After the labelling reaction, probes were purified of free isotope using spin columns (5' to $3^{\prime}$, Boulder, $\mathrm{CO}$ ). Radioactive counts were determined using a betacounter. The final amount of each probe in the hybridization reaction was equivalent to $200000 \mathrm{cpm}$.

\section{Results}

\section{I. Sensitivity of multiplex $P C R$}

The sensitivity of the reaction was measured by serial dilution of the HIV-I genome carrying Z6 plasmid (Perkin Elmer Cetus, Norwalk) in the background of $1 \mu \mathrm{g}$ of H9 DNA. As few as two or three copies of the plasmid could be detected when primers corresponding to the GAG, POL and ENV regions were used individually or in combination (Fig. 1). A similar degree of sensitivity was observed when HIV-2 primers were used individually or in combination for the amplification of the plasmid pRod 10 containing the HIV-2 ROD genome (Fig. 2). Although less intense signals were observed when the simultaneous amplification of three genome regions was compared with the single region amplification, the sensitivity of the reaction in terms of copy number was the same. Analogous results were obtained when DNA extracted from H9 cells infected with either IIIV-l (IIIb) or IIIV-2 (ROD) was serially diluted and amplified by PCR (not shown).

\subsection{Specifity of multiplex $P C R$}

Although primers were selected from highly specific regions of HIV-1 and HIV-2, we further investigated the specificity by amplification of different strains of each virus. When DNA extracted from the IIIB, MN and Z6 strains of HIV-I was amplified by multiplex PCR using HIV-1 primers, all three strains were detected. Similarly, multiplex PCR with HIV-2 primers detected the Rod, CAM and Ms strains. In 

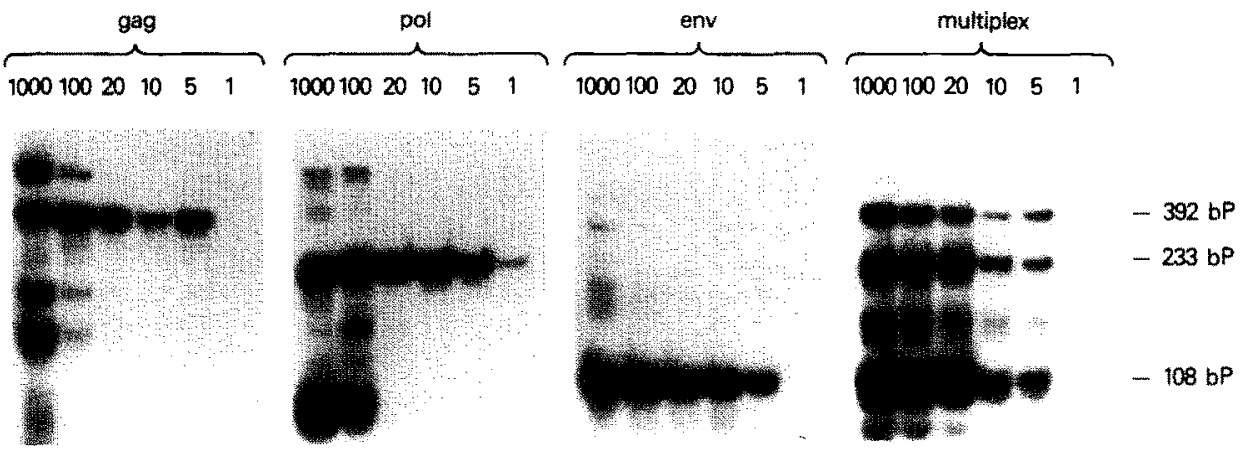

Fig. 2. Single and multiplex PCR sensitivity for HIV-2 amplification. The numbers on top indicate the copy number of pRod 10 plasmid. Genomic position and size of the amplified fragments are also indicated.

contrast, HIV-I multiplex PCR failed in the amplification of HIV-2, and HIV-2 multiplex PCR did not detect HIV-I DNA (not shown).

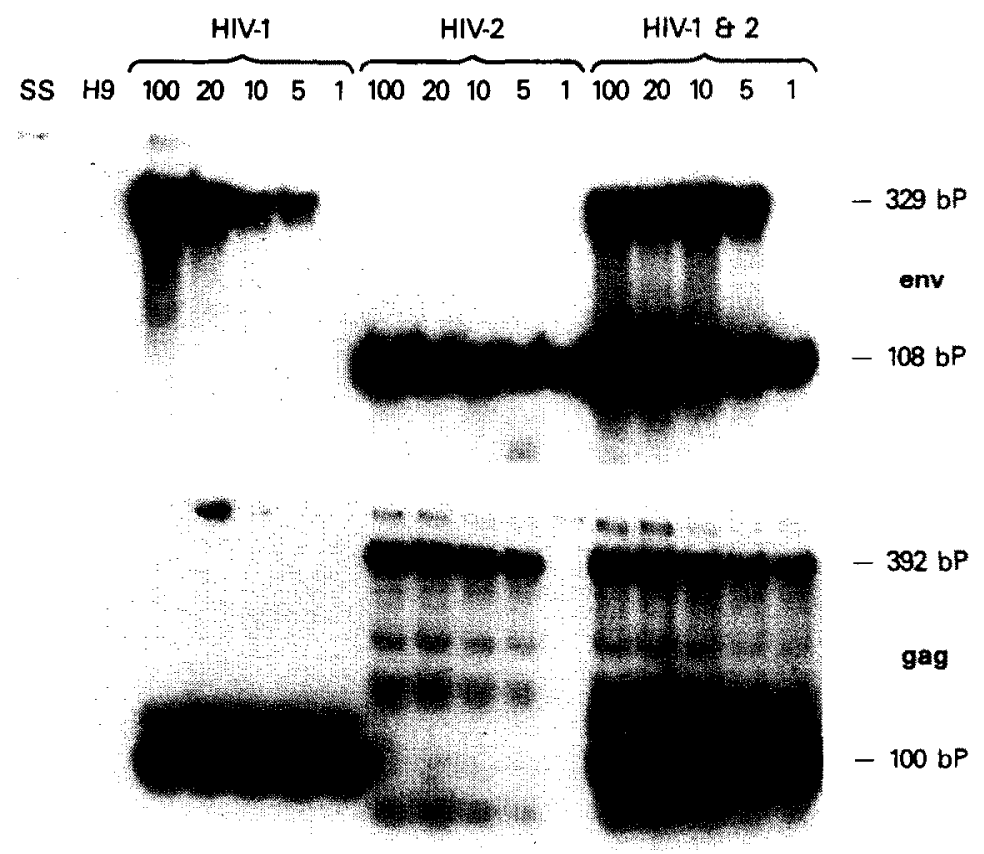

Fig. 3. Coamplification of the ENV or GAG regions of both HIV-1 and HIV-2. Primer pairs corresponding to the ENV region (upper haln) or the GAG region (lower haln of HIV-I and HIV-2 were used to amplify DNA of one of two of the viruses. The numbers on top indicate the copy number of $Z 6$ and pRod 10 plasmid DNA. 


\subsection{Effect of $\mathrm{Mg}^{2--}$ concentration in multiplex $P C R$}

Multiplex PCR was performed at different concentrations of $\mathrm{Mg}^{2}$. While POL and ENV HIV-1 primers appeared to perform marginally better at higher concentrations of $\mathrm{Mg}^{2+}$ when compared with the GAG primers, the standard concentration of $1.5 \mathrm{mM}$ showed comparable results with all three primer pairs together. Similarly HIV-2 primers performed optimally at $1.5 \mathrm{mM}$ (not shown).

\subsection{Coamplification of $\mathrm{HH}-\mathrm{I}$ and $\mathrm{HIV}-2$}

We further investigated the potential of multiplex PCR by attempting to amplify in a single reaction both HIV-1 and HIV-2. Amplification in a reaction mixture containing a $0.25 \mu \mathrm{M}$ concentration of each ENV or GAG primers for both viruses was carried out under the same conditions indicated above. The different sizes of the amplified products in HIV-1 and HIV-2 enabled us to detect both viruses in the same PCR reaction. Between 1 and 5 copies of viral DNA for each virus could be routinely detected when the GAG or the ENV primers were used (Fig. 3).

\subsection{Evaltation of $\mathrm{HH}-\mathrm{H}$ and $\mathrm{HIV-2}$ infected individuats using multipler $\mathrm{P} C \mathrm{C}$}

The multiplex PCR technique was used to evaluate DNA extracted from nine HIV-1 and five HIV-2 infected individuals. Multiplex PCR for HIV-I detected all HIV-1 samples and did nol give any signal in the HIV-2 samples (Fig. 4). Multiplex

\section{$\begin{array}{lllllllllllllll}1 & 2 & 3 & 4 & 5 & 6 & 7 & 8 & 9 & 10 & 11 & 12 & 13 & 14\end{array}$}

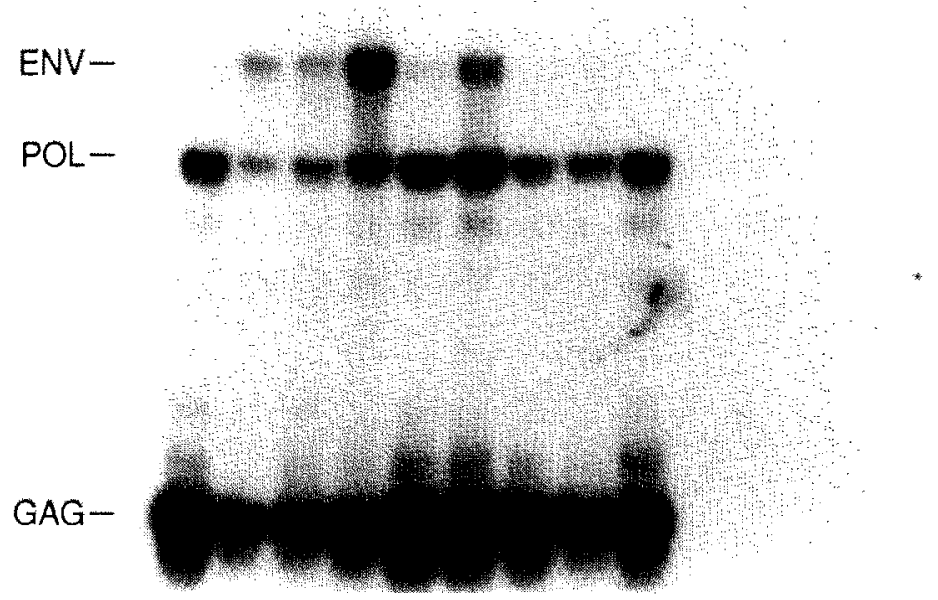

Fig. 4. Evaluation of clinical specimens by HIV-1 multiplex PCR. Lanes 19 correspond to the amplification of DNA extracted from HIV-1 scropositive. HIV-2 seronegative individuals. Lanes 10 la corrispond to HIV-l seronegative, HIV-2 seropositive individuals. 


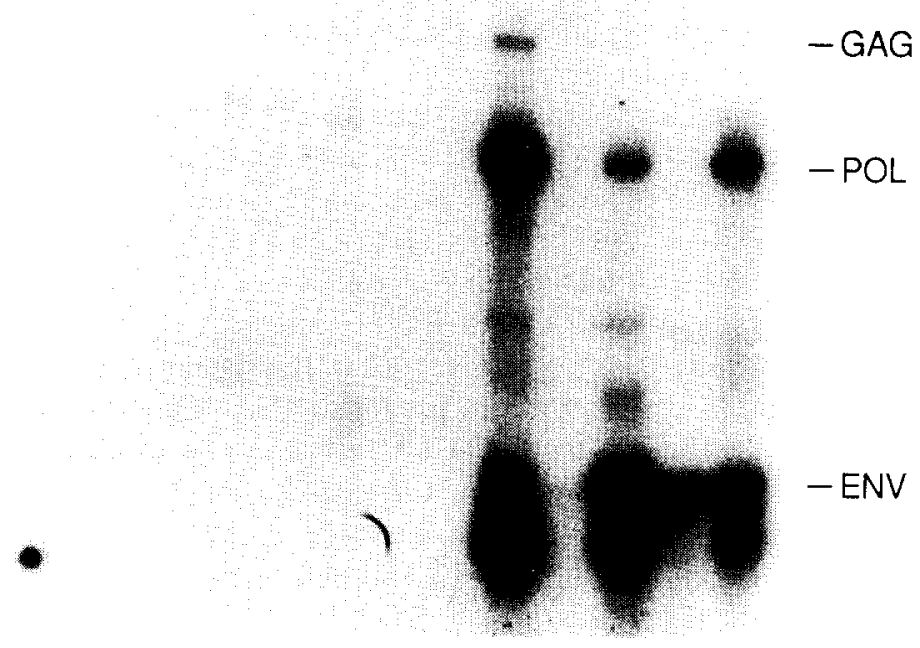

Fig. 5. Evaluation of clinical specimens by HIV-2 multiplex PCR. Lanes $1-14$ are the same as in Fig. 4.

PCR for HIV-2 identified four out of five HIV-2 infected samples and did not detect any of the HIV-1 samples (Fig. 5).

While ENV, GAG and POL regions were detected with equal efficiency when multiplex PCR was used in the detection of HIV-1 DNA in infected cell lines, our preliminary analysis of clinical samples revealed that amplification occurred only with the GAG primers and after 35 cycles of amplification (not shown). We then modified several parameters to standarize the multiplex PCR for detection of HIV-1 in clinical specimens. A twofold increase in the concentration of POL and ENV primers $(0.5 \mu \mathrm{M}$ final concentration for POL and ENV, and $0.25 \mu \mathrm{M}$ for GAG) and using 5 units of Taq enzyme per reaction enabled us to detect all three bands in most of the samples after amplification for 35 cycles.

\section{Discussion}

The remarkable genetic variability of HIV-1 (Goudsmit et al., 1991) and especially HIV-2 isolates (Schulz et al., 1990) contributes significantly to problems in the detection of these viruses by PCR. Amplification of several regions of the viral genome using different primer pairs is one of the approaches to overcome the problem (Laure et al., 1988; Ou et al., 1988). Amplification of different regions has been performed conventionally in individual reactions. This approach is time consuming and is not feasible when the size of the clinical samples is limited (Hewlett et al., 1989). We, therefore, developed a multiplex PCR technique in which three different genomic regions of HIV-1 or HIV-2 are amplified in the same reaction and detected after a single liquid hybridization reaction with radioactive probes corresponding to 
each one of the amplified regions. The technique is both specific and sensitive. Each primer pair identified the correct virus type for three prototypic strains of that type and none of the other virus types. Multiplex PCR produced all three expected fragments with each one of the target strains.

Sensitivity of these reactions was consistent for detection of one to ten copies of the target. It is important to note that there was no compromise in assay sensitivity as a result of amplification of multiple regions in the same reaction mixture.

In earlier experiments we observed that although each primer pair amplified the targeted sequence when used individually, a combination of all three primer pairs did not yield any signal in multiplex PCRs, probably as a result of primer-dimer formation (data not shown). It has been reported that primer sets containing a high degree of complementarity are subject to primer-dimer formation at room temperature and can be elongated by Tay enzyme, generating undesired PCR products (Willams et al., 1989). Technically it is not always feasible to avoid complementarity when several primers are used in the same reaction mixture. We addressed this by incorporating the hot-start technique in the multiplex format (D'Aquila et al., 1991). The number of amplification cycles is also an important factor to consider in multiplex PCR. Thermocycling for 3335 cycles allowed us to detect wo or three copics of HIV-I and HIV-2 target DNA. Reduction in cycle number often resulted in the loss of sensitivity. Amplification for 35 cycles oceasionally generated additional bands in standard and multiplex PCRs (Fig. 2): however, the presence of these additional bands did not impede the detection of the principal bands as the latter ones are more conspicuous and easy to identify. We performed liquid hybridization to enhance the efficiency of testing in terms of time and the number of samples that can be analyzed in a given experiment. If proviral detection is the key issuc of multiplex PCR, it may be more appropriate 10 perform 35 amplification cycles in order 10 assure detection of samples with a low copy number.

One of the most important problems in the detcetion of target DNA by PCR is the rate of false positivity due to sample contamination with amplified $D N A$ from previous PCR reactions (Clewley et al., 1989). To reduce the risk of contamination. we incorporated the Uracyl $N$-glycosylase enzyme (Longo et al., 1990) and substituted dideoxynucleotide thymidine with uracil in our multiplex PCR mixture. A final concentration of $200 \mu \mathrm{M}$ for each $\mathrm{dNTP}(\mathrm{d} A$. dU. dC. dG) yielded the best results (not shown).

In addition to the multiplex PCR described, it is important to point out that we have developed a sensitive and highly specific set of primers for HIV-2 detection. The low sensitivity of HIV-2 PCR has been improved by techniques such ats nested PCR (Grankvist et al., 199lb) or sometimes probing with a radioaclive probe after carrying out nested PCR (George el al., 1992). Although nested PCR yields a high sensitivity for HIV-2, it is not compatible with the incorporation of the Uracyl $N$ glycosylase system for degradation of possible contaminating DNA from previous amplifications. If $\mathrm{PC} \mathrm{K}$ is to be used in a diagnostic setting, measures for reducing the risk of contamination. resulting in false positive reactions, are critical and extremely important for proper interpretation of results.

We lested the ability of multiplex PCR to detect HIV-I and HIV-2 in clinical 
samples. All samples from HIV-I seropositive individuals were detected by multiplex PCR (Fig. 4). Interestingly, while GAG and POL regions were detected in all samples, the ENV region was not amplified in some of them. Despite the fact that sample number was small in our study, the absence of ENV signal in some of the samples may reflect the variability of this genomic region. Multiplex PCR for HIV-2 detected four out of five samples from HIV-2 seropositive individuals (Fig. 5). One sample yielded a signal in all three genomic regions, two samples showed amplification of POL and ENV but not GAG region, and one sample only gave a signal in the ENV region. Evaluation of clinical specimens by multiplex PCR revealed a broader spectrum of band pattern for HIV-2, in agreement with the higher variability of the HIV-2 strains. The fact that one of the HIV-2 seropositive individuals was not detected by PCR suggests reduced sensitivity of HIV-2 PCR compared with serology. The lower sensitivity of HIV-2 PCR has been attributed to the presence of fewer infected cells or low copy number in HIV-2 versus HIV-1 seropositive individuals (Grankvist et al., 1992b). Improved sensitivity of HIV-2 PCR may be achieved with an increase of the amount of DNA in the amplification reaction as demonstrated for HIV-1 (Lee et al, 1991). It is interesting to note that the undetected HIV-2 sample in our study was derived from an individual with relatively higher CD4 cell counts $(826 / \mu 1)$. Our limited study in clinical specimens seems to indicate that GAG and ENV primers for HIV-L and HIV-2 respectively, amplify the target DNA with greater efficiency than other sequences in the multiplex reaction; however, the additional set of primers were included to ensure reactivity in the face of false negatives, due to variation in the other genomic regions.

The multiplex PCR method also enabled us to detect in the same reaction both HIV -1 and HIV-2 proviruses with high specificity and sensitivity. This may be useful for the detection of coinfections or single virus infections in geographic areas where both HIV-1 and HIV-2 coexist (De Cock et al., 1991; Pfutzner et al., 1992). It would also facilitate the differentiation between dual and single infections when cross-reactivity is observed in Western blots (Leonard et al., 1993) and resolve indeterminate blot patterns seen in HIV testing. Analysis of DNA from individuals with serological reactivity to both HIV-1 and HIV-2 are in progress, in order to further evaluate the utility of our multiplex amplification technique.

\section{References}

Clewley, J.P. (1989) The polymerase chain reaction, a review of the practical limitations for Human Immunodeficiency Virus diagnosis. J. Virol. Methods 25, $179 \cdot 188$.

D'Aquila, R.T., Bechtel, L.J., Videler, J.A., Eron, J.J., Gorczyca, P. and Kaplan, J.C. (1991) Maximum sensitivity and specificity of PCR by pre-amplification heating. Nucleic Acids Res. 19. 3749.

De Cock, K.M., Brun-Vezinet, F, and Soro. B. (1991) HIV-1 and HIV-2 infections and AIDS in West Africa. AIDS 5 (suppl. 1), S21 S28.

Ehrlich, G.D., Greenberg. S. and Abbot, M.A. (1990) Detection of human T-cell lymphoma/leukemia viruses. In M.A. Innis, D.H. Gelfand, J.J. Sninsky and T.J. White (Eds.). PCR Protocol. A Guide to Methods and Applications. Academic Press. California, pp. 333-334.

George, J.R., Ou, C., Parekh, B., Brattegard. K., Brown, V.. Boateng. E. and De Cock, K. M. (1992) Prevalence of HIV-1 and HIV -2 mixed infections in Coted lvoire. Lancet $340,337-339$. 
Goudsmit, J., Back, N.K. and Nara, P.L. (1991) Genomic diversity and antigenic variation of HIV-1: links between pathogenesis, epidemiology and vaccine development. FASEB J. S, 2427.2436.

Grankvist, O., Gustafsson, A., Bredberg-Raden, U., Pallangyo, K., Mhalu, F., Biberfeld, P.. Biberfeld, G. and Wadell, G. (1991) Selection of primers of optimal sensitivity for the detection of HIV-1 from Africa and Europe by polymerase chain reaction. AIDS 5, 575-578.

Grankvist, O., Bredberg-Raden, U., Gustafsson, A., Albert, J., Albino, P., Andreasson, P.A., Naucler, A., Biberfeld, G. and Wadell, G. (1992) Improved detection of HIV-2 DNA in clinical samples using a nested primer-based polymerase chain reaction. J. Acq. Imm. Def. Syn. 5, 286-293.

Hewlett, I.K., Ruta, M., Cristiano, K., Hawthorne, C.A. and Epstein, J.S. (1989) Co-amplification of multiple regions of the HIV-1 genome by the polymerase reaction: potential use in multiple diagnosis. Oncogene 4, 1149-1151.

Laure, F., Courgnaud, V., Rouzioux, C., Blanche, S., Veber, F., Burgard, M., Jacomet, C., Griscelli, C. and Brechot, C. (1988) Detection of HIV-I DNA in infants and children by means of the polymerase chain reaction. Lancet ii, 538-541.

Lee, T.Z., El-Amad, Z., Reis, M., Adams, M., Donegan, E.A., O'Brien, T.R., Moss, A.R. and Busch. M.P. (1991) Absence of HIV-1 DNA in high-risk seronegative individuals using high-input polymerase chain reaction. AIDS 5, 1201-1207.

Leonard, G., Chaput, A., Courgnaud, V., Sangare, A., Denis, F. and Brechot, C. (1993) Characterization of dual IIIV-1 and HIV-2 serologic profiles by polymerase chain reaction. AIDS 7, 11851189.

Longo, M., Berninguer, M. and Hartley, J. (1990) Use of uracil DNA glycosylase to control carry-over contamination in polymerase chain reactions. Gene 93, 125-128.

Myers, G., Kurber, B.. Berzofsky, J.A., Smith, R.F. and Pavlakis, G.N. (1992) Human Retroviruses and AIDS. A Compilation and Analysis of Nucleic Acid and Amino Acid Sequences. Los Alamos National Laboratory, Los Alamos.

Ou. C., Kwok, S., Mitchell, S.W., Mack, D.H., Sninsky, J.J., Krebs, J.W. Feorino, P., Warfield, D. and Schochetman, G. (1988) DNA amplification for direct detection of HIV-1 in DNA of peripheral blood mononuclear cells. Science 239, $295-297$.

Pfutzner. A., Dietrich, U., von Eichel, U., von Briesen. H., Brede, H.D., Maniar. J.K, and RubsamennWaigmann. H. (1992) HIV-1 and HIV-2 infections in a high-risk population in Bombay. India: Evidence for the spread of HIV-2 and presence of a divergent HIV-I subtype. J. Acq. Imm. Def. Syn. 5 , 972-977.

Sambrook, J., Fritsch, E.F. and Maniatis, T. (1989) Molecular Cloning. A Laboratory Manual. Second edition. Cold Spring Harbor Laboratory Press, New York.

Schulz, T.F., Whitby, D., Hoad, J.G., Corrah, T., Whittle, H. and Weiss, R.A. (1990) Biological and molecular variability of human immunodeficincy virus type 2 isolates from the Gambia. J. Virol. 158. $1170-1176$

Williams, J.F. (1989) Optimization strategies for the polymerase chain reaction. BioTechniques 7.762 768 . 